\title{
Inhibitory Concentration Test
}

National Cancer Institute

\section{Source}

National Cancer Institute. Inhibitory Concentration Test. NCI Thesaurus. Code C116117.

A laboratory test to determine the concentration of a substance that will inhibit a biological or biochemical function, such as microorganism growth or enzymatic activity. 